\title{
Interstitial Pneumonitis during Imatinib Therapy in a Patient with Gastrointestinal Stromal Tumor: A Case Report
}

\section{Youssef Seddik*, Sami Aziz Brahmi and Said Afqir}

Medical Oncology Department, University Hospital Mohammed VI, Medical School of Oujda, University Mohammed the First, Oujda, Morocco

\begin{abstract}
Introduction: Imatinib is approved for the treatment of chronic myeloid leukemia and for gastro intestinal stromal tumors. It is generally well tolerated with mild common toxicities such as diarrhea, fatigue, skin rash and edema, however pulmonary complications are uncommon.
\end{abstract}

Case presentation: In May 2013, a Moroccan 81-year-old man without medical history underwent an emergency wedge resection of the stomach for severe hematemesis with hemodynamic instability. The pathology report showed a gastric gastro intestinal stromal tumor. In July 2013, Imatinib $400 \mathrm{mg}$ per day was started, the patient showed good tolerance to the drug, although mild diarrhea was present. After 16 months, the patient showed a sudden alteration of his performance status, dyspnea, productive cough and fever. Chest X-rays and computed tomography revealed a left pulmonary interstitial syndrome with bilateral pleural effusions. As these findings were highly suggestive of Imatinib-induced interstitial pneumonitis, Imatinib was discontinued. In the meantime, the patient was given oral prednisone: $60 \mathrm{mg}$ daily for 10 days. Under the corticosteroid therapy, his symptoms and radiological findings were resolved. The patient comes in regularly for symptomatic control without any signs of tumor's relapse.

Conclusion: Physicians should consider the possibility of Imatinib-induced pulmonary toxicities when patients develop respiratory symptoms or abnormal radiologic features during Imatinib treatment. The usual treatment is to discontinue the drug, and administer corticosteroids.

Keywords: Imatinib; GIST; Unusual pulmonary toxicities; Corticosteroids

Abbreviations: GIST: Gastrointestinal Stromal Tumor; PDGFRA: Platelet-Derived Growth Factor Receptor a; CML: Chronic Myeloid Leukemia; CT: Computer Tomography; ILD: Interstitial Lung Disease

\section{Introduction}

Gastrointestinal stromal tumors (GISTs) are rare tumors, with an estimated unadjusted incidence of around 1/100 000/ year [1]. It is a result of mutations in KIT tyrosine kinase and in platelet-derived growth factor receptor $\alpha$ (PDGFRA) $[2,3]$. These mutations are targeted by Imatinib Mesylate in the metastatic,adjuvant and neoadjuvant setting $[4,5]$. This drug blocks also the BCR-ABL tyrosine kinase in chronic myeloid leukemia (CML) [6]. Imatinib is generally well tolerated with mild common toxicities such as diarrhea, fatigue, skin rash and edema, however pulmonary complications are uncommon [6] we report a case of Imatinib-induced pulmonary toxicity which was treated successfully.

\section{Case Presentation}

In May 2013, a Moroccan 81-year-old man without medical history underwent an emergency wedge resection of the stomach for severe hematemesis with hemodynamic instability. The pathology report showed a gastric GIST (CD117 and CD34 positive, cytokeratin, actin and desmin negative, moderate risk according to Miettinen $\mathrm{M}$ and Lasota J classification, the resection margins were clear). Postoperative total body computer tomography (CT) showed no evidence of metastases. In July 2013, Imatinib $400 \mathrm{mg}$ per day was started, the patient showed good tolerance to the drug, although mild diarrhea was present, until 26 December 2014, when the patient showed a sudden alteration of his performance status, dyspnea, productive cough and fever. Chest X-rays and computed tomography revealed a left pulmonary interstitial syndrome with bilateral pleural effusions (Figure 1). As these findings were highly suggestive of Imatinib-induced interstitial pneumonitis, Imatinib was discontinued. In the meantime, the patient was given oral prednisone: $60 \mathrm{mg}$ daily for 10 days. Under the corticosteroid therapy, his symptoms and radiological findings were resolved (Figure 2). It was decided to permanently discontinue treatment with this drug in adjuvant setting and monitor the patient with routine follow-up.

\section{Discussion}

Gastrointestinal stromal tumors (GISTs) are rare tumors, which are thought to arise from the intestinal cells of Cajal that are found throughout the gastrointestinal tract, regulating peristalsiss [7]. GISTs usually arise from the stomach, followed by the small intestine, rectum and other locations in the gastro-intestinal tract [8]. The most common metastatic sites are the liver and peritoneum $[9,10]$.

Known to be refractory to conventional chemotherapy or radiation, GISTs are primarily a result of oncogenic mutations in the KIT(CD117) tyrosine kinase as reported in 1998 by Hirota et al. [2], subsequently, it was found that mutations in PDGFRA can be an alternate pathway for oncogenesis [3]. These mutations are targeted by Imatinib Mesylate, which has revolutionized the GIST's prognosis in the metastatic, adjuvant or neo adjuvant setting $[4,5]$.

*Corresponding author: Youssef Seddik, Medical Oncology Department University Hospital Mohammed VI, Medical School of Oujda, University Mohammed the First, Oujda, B.P. 524, Oujda 60000, Morocco, Tel: +212 5365-00612; E-mail: seddiky2@gmail.com

Received July 10, 2015; Accepted August 11, 2015; Published August 14, 2015

Citation: Seddik Y, Brahmi SA, Afqir S (2015) Interstitial Pneumonitis during Imatinib Therapy in a Patient with Gastrointestinal Stromal Tumor: A Case Report. J Cancer Sci Ther 7: 269-271. doi:10.4172/1948-5956.1000361

Copyright: $\odot 2015$ Seddik $Y$, et al. This is an open-access article distributed unde the terms of the Creative Commons Attribution License, which permits unrestricted use, distribution, and reproduction in any medium, provided the original author and source are credited. 


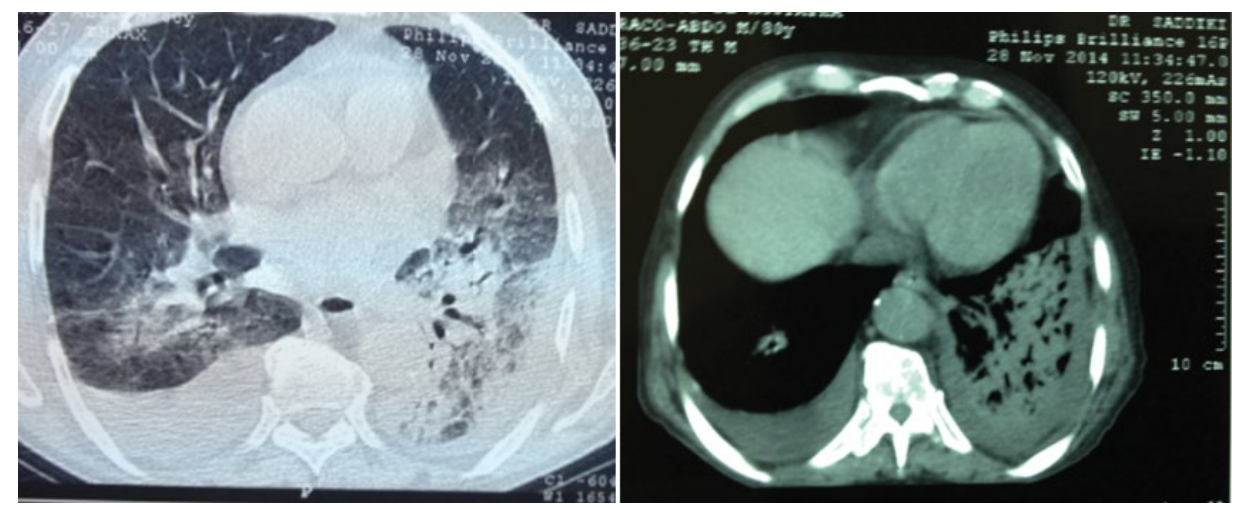

Figure 1: Chest computer tomography revelead a left pulmonary interstitial syndrome with bilateral pleural effusions.
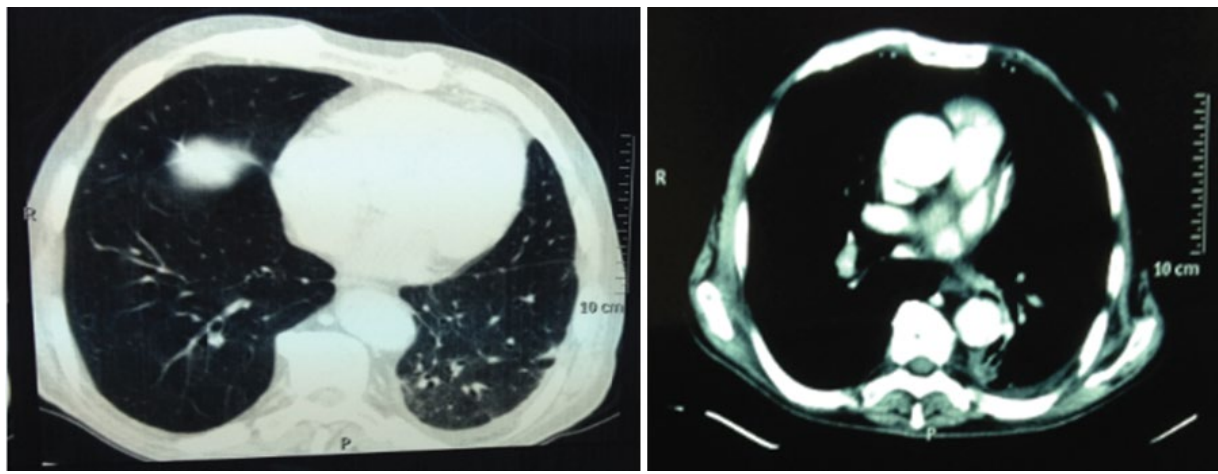

Figure 2: Chest computer tomography showed resolution of radiological abnormalities.

Imatinib is generally well tolerated with mild frequent toxicities such as diarrhea, fatigue, skin rash and edema, however pulmonary complications are uncommon, most often related to the pulmonary edema and pleural effusion [6-11] Interstitial pneumonitis during Imatinib therapy is a rare entity $[12,13]$.

Although the pathophysiology of Imatinib-induced interstitial pneumonitis has not been identified clearly until now, the noncytotoxic or cytotoxic types are suggested as possible mechanisms [14]. The noncytotoxic type manifests as eosinophilia pneumonia, hypersensitive pneumonitis, or obstructive bronchiolitis, whereas the cytotoxic pattern manifests as interstitial edema, lymphocyte infiltration, and destruction of alveolar epithelial cells. In addition, Imatinib aggravates interstitial pneumonitis by inhibiting PDGF tyrosine kinase, which leads to acute lung injury $[15,16]$.

Ohnishi et al. collated data from 27 patients, among 5000 patients with CML and 500 patients with GIST, who appeared to have developed interstitial lung disease (ILD) while on Imatinib therapy [17]. The median period until development of ILD was 49 days (range: 10-282 days) and the median daily dose of Imatinib was $400 \mathrm{mg}$ (range: $200-600 \mathrm{mg}$ ) at the time ILD was diagnosed. However, there was no clear correlation between the development of ILD and either the dose or duration of Imatinib therapy. But, the incidence of the disease seemed higher in patients who had pre-existing pulmonary diseases. Our patient had no previous lung disease. He had tolerated Imatinib well until month 16 of treatment, when a serious pulmonary complication occurred. The dosage of Imatinib was $400 \mathrm{mg} /$ day. The diagnosis is made based on history, clinical symptoms, radiological findings, and pathological results. Chest radiographs show diverse patterns such as a hypersensitivity reaction, interstitial pneumonitis, cryptogenic-organizing pneumonia, nodular or peribron-chovascular lesions, and diffuse alveolar damage [17]. Our patient had a sudden alteration of his performance status, dyspnea, productive cough and fever. The radiological examination revealed a left pulmonary interstitial syndrome with bilateral pleural effusions. The majority of patients [13-17] either improved or had complete resolution of ILD with the discontinuation of Imatinib and the addition of low doses of short-term steroids [17]. It was confirmed that our patient had druginduced pulmonary toxicities due to improvement of his symptoms and radiological findings by withdrawal of Imatinib and initiating steroid therapy.

To our knowledge, our report represents the first published case of interstitial pneumonitis and bilateral pleural effusions induced by Imatinib in Morocco.

\section{Conclusion}

Physicians should consider the possibility of Imatinib-induced pulmonary toxicities when patients develop respiratory symptoms or abnormal radiologic features during Imatinib treatment. The usual treatment is to discontinue the drug, and administer corticosteroids.

\section{Acknowledgments}

The authors would like to thank Dr. Hassan Seddiki who provides us the radiological figures. 
Citation: Seddik Y, Brahmi SA, Afqir S (2015) Interstitial Pneumonitis during Imatinib Therapy in a Patient with Gastrointestinal Stromal Tumor: A Case Report. J Cancer Sci Ther 7: 269-271. doi:10.4172/1948-5956.1000361

\section{Consent}

Written informed consent was obtained from the patient for publication of this case report and accompanying images. A copy of the written consent is available for review by the Editor-in-Chief of this journal.

\section{Competing interests}

The author(s) declare that they have no competing interests

\section{Author's contributions}

YS performed literature review, composed this case report and manuscrip writing. SAB was involved in the collection and assembly of the data. SA corrected and approved the final version of the manuscript. All authors read and approved the final manuscript.

\section{References}

1. Nilsson B, Bumming P, Meis-Kindblom JM (2005) Gastrointestinal stromal tumors: the incidence, prevalence clinical course, and prognostication in the pre-imatinib mesylate era-a population based study in western Sweden. Cancer 103: 821-829.

2. Hirota S, Isozaki K, Moriyama Y, Hashimoto K, Nishida T, et al. (1998) Gain-offunction mutations of $\mathrm{c}$-kit in human gastrointestinal stromal tumors. Science 279: $577-580$.

3. Hirota S, Ohashi A, Nishida T, Isozaki K, Kinoshita K, et al. (2003) Gain-offunction mutations of platelet-derived growth factor receptor alpha gene in gastrointestinal stromal tumors. Gastroenterology 125: 660-667.

4. Heinrich MC, Corless CL, Demetri GD, Blanke CD, von Mehren M, et al. (2003) Kinase mutations and imatinib response in patients with metastatic gastrointestinal stromal tumor. J Clin Oncol 21: 4342-4349.

5. Okuda K, Weisberg E, Gilliland DG, Griffin JD (2001) ARG tyrosine kinase activity is inhibited by STI571. Blood 97: 2440-2448.

6. Kantarjian H, Sawyers C, Hochhaus A, Guilholt F, Schiffer C, et al. (2002) Hematologic and cytogenic responses to imatinib mesylate in chronic myelocytic leukemia. N Engl J Med 346: 645-652.
7. Rubin BP, Fletcher JA, Fletcher CD (2000) Molecular insights into the histogenesis and pathogenesis of gastrointestinal stromal tumors. Int $\mathrm{J}$ Surg Pathol 8: 5-10.

8. Foo WC, Liegl-Atzwanger B, Lazar AJ (2012) Pathology of gastrointestinal stromal tumors. Clin Med Insights Pathol 5: 23-33.

9. Joensuu H, Hohenberger P, Corless CL (2013) Gastrointestinal stromal tumour Lancet 382: 973-983.

10. Joensuu H, Vehtari A, Riihimäki J, Nishida T, Steigen SE, et al. (2012) Risk of recurrence of gastrointestinal stromal tumour after surgery: an analysis of pooled population-based cohorts. Lancet Oncol 13: 265-274.

11. Goldsby R, Pulsipher M, Adams R, Coffin C, Albritton K, et al. (2002) Unexpected pleural effusions in 3 pediatric patients treated with STI-571. J Pediatr Hematol Oncol 24: 694-695.

12. Rosado MF, Donna E, Ahn YS (2003) Challenging problems in advanced malignancy: case 3 . Imatinib mesylate-induced interstitial pneumonitis. J Clin Oncol 21: 3171-3173.

13. Isshiki I, Yamaguchi K, Okamoto S (2004) Interstitial pneumonitis during imatinib therapy. Br J Haematol 125: 420.

14. Yokoyama T, Miyazawa K, Kurakawa E, Nagate A, Shimamoto T, et al (2004) Interstitial pneumonia induced by imatinib mesylate: pathologic study demonstrates alveolar destruction and fibrosis with eosinophilic infiltration. Leukemia 18: 645-646.

15. Snyder LS, Hertz MI, Peterson MS, Harmon KR, Marinelli WA, et al. (1991) Acute lung injury: pathogenesis of intraal-veolar fibrosis. J Clin Invest 88: 663-673.

16. Walsh J, Absher M, Kelley J (1993) Variable expression of platelet-derived growth factor family proteins in acute lung injury. Am J Respir Cell Mol Biol 9 . 637-644.

17. Ohnishi K, Sakai F, Kudoh S, Ohno R (2006) Twenty-seven cases of drug induced interstitial lung disease associated with imatinib mesylate. Leukemia 20: 1162-1164. 